\title{
ESTUDIOS
}

\section{Poesía y Sociedad en Hispanoamérica}

"Atravesamos unos tiempos calamitosos en los cuales no es posible hablar ni callar sin peligro": estas palabras que parecen aludir a nuestra época, fueron escritas por el gran pensador valenciano Juan Luis Vives en el siglo Xvi. Ya desde entonces se perfilaban las dos tendencias, conformista e inconforme, en el terreno de las ideas, lo cual significa en el vocabulario de hoy la toma de posición de los hombres de letras en las filas del conformismo o del no-conformismo. Las cuestiones más debatidas eran la Contrarreforma, el derecho de España a la conquista del Nuevo Mundo, la cruzada para redimir a los indios llamados infieles. $\mathrm{Si}$ bien es cierto que la literatura de protesta y la literatura revolucionaria son fenómenos contemporáneos que obedecen a la actual etapa sociológica, es igualmente un hecho indiscutible que la literatura hispanoamericana, desde sus inicios fue fruto del estado social de las colonias. No hubo lo que se llama propiamente literatura de evasión en la época colonial. El escritor se encuentra comprometido desde los ptimeros días del descubrimiento, como se puede ver en la actitud de los poetas que se sienten responsables ante la sociedad y la "conciencia cristiana".

Es preciso no olvidar que los escritos debían someterse a la censura eclesiástica, al Consejo de Indias y a los censores del Santo Tribunal de la Inquisición, lo cual obligaba a los autores a expresarse con cautela, valerse de hábiles recursos y velar sus intenciones retorciendo artísticamente la forma. En sus Elegias de Varones Ilustres de Indias, Juan de Castellanos puso en boca de Drake acerbas críticas a la conquista española, que no escaparon a los ojos perspicaces del censor del Consejo de Indias, quien condenó a la destrucción seiscientas cincuenta octavas del Discurso del corsario inglés, lo cual en realidad no significó desmedro notable a la extensión del poema que contiene 150,000 versos, constituyendo la 
mayor crónica rimada del Descubrimiento y la Conquista del Nuevo Mundo. El párroco de Tunja, antiguo pescador de perlas, posee el aliento suficiente para escribir durante su larga vida, pero no está dotado de la visión cromática del mundo que caracteriza a Alonso de Ercilla. Es tan sólo un modesto notario de la poesía, que asienta en su libro los hechos, en versos endecasílabos, "al itálico modo". Ercilla tiene una formación renacentista y sabe mirar e interpretar el paisaje americano, construyendo con sus originales percepciones las más vivas metáforas. En las postrimerías del siglo xvi y comienzos del xvil, nuevos cultores de la poesía siguen estos modelos y salen a la luz El Peregrino Indidno de Saavedra Guzmán, "diario rimado de las operaciones militares de Hernán Cortés", Arauco Damado de Pedro de Oña, Grandeza Mexicana de Bernardo de Balbuena, Armas Antáricas de Juan de Miramontes. La poesía es el espejo donde se refleja la suma de ideas o de hechos de la época, así como las experiencias de una sociedad nueva.

Las navegaciones, los reconocimientos de las costas desconocidas, los desembarcos y las expediciones al interior de las tierras vírgenes, los combates con los indios y las hostilidades entre españoles, constituyen la temática vertida en los estrechos moldes de las octavas reales. El poema épico se convierte en un documento histórico que ayuda a comprender la naciente organización social de las colonias. En las Armas Antárticas se relata, entre otros episodios, la batalla de Iñaquito, librada por Gonzalo Pizarro, jefe de los Encomenderos, contra el virrey Blasco Núñez de Vela, portador de las ordenanzas reales de protección a los indios contra los desmanes de los conquistadores. La poesía denuncia el hecho de que los españoles trajeron a América la semilla de la guerra civil. Los poetas no ocultaban su simpatía por una u otra de las facciones adversas, aunque en general se imponia la actitud conformista en favor del Poder Real y la Iglesia.

La sociedad colonial no era simplemente la sociedad hispánica trasladada al Nuevo Mundo sino enriquecida, al mismo tiempo, por los usos y costumbres de los pueblos sometidos. La ciudad, la calle, la plaza, la vivienda, no eran completamente españolas: la ciudad disponía de mayor espacio y poseía un trazado geométrico de rúas paralelas; la calle era un escenario donde se representaba diariamente la comedia de la cortesía, cuyos personajes eran el encomendero, el eclesiástico, el leguleyo y el soldado. La plaza mayor constituía el sitio apropiado para las diversiones populares, las corridas de toros, el mercado y las manifestaciones cívicas. Era el corazón de la ciudad, y por esta razón alli se concentraban los símbolos de los poderes pontificio y regio y de la representación popular, 
o sea: el Palacio Arzobispal, el Palacio de Gobierno, el Palacio Municipal o Ayuntamiento $y$, finalmente, las prisiones y el patíbulo. La arquitectura civil copiaba a la religiosa de tal modo que la casa era un convento en pequeño, con su patio interior cuadrangular y sus columnas ventrudas que sostenían los altos corredores. El español encontró holgura en América y tiempo para sus prácticas religiosas, pero también para la tertulia y el juego de naipes. En ocasiones las veladas se enardecian con la crítica a las instituciones coloniales, a los impuestos y a la mala administración pública. En el poema épico Arauco Domado, Pedro de Oña empleó el consabido recurso del sueño de uno de sus personajes para trasladar la atención del lector a otro extremo de América y narrar la re. belión del pueblo de Quito contra las alcabalas, con el consiguiente castigo de los cabecillas. El poeta no sólo había sido testigo ocular sino actor en ese drama de un pueblo. Cuando el general de arcabuceros Pedro de Arana levantó un ejército mercenario para marchar contra los rebeldes, Pedro de Oña ofreció sus servicios y obtuvo como recompensa el cargo de Corregidor de Jaén de Bracamoros. En medio de la exuberante vegetación de esa tierra ecuatorial, encontró la paz y el ocio propicios para escribir sus estrofas en alabanza de los capitanes que sofocaron la Revolución de las Alcabalas, primer movimiento auténticamente popular de América al finalizar el siglo xvi. Pero, el poeta cortesano, adulador del virrey de Lima, olvidó de quemar incienso a los pies de algunas autoridades de la Real Audiencia de Quito, la cual obtuvo que se suprimiera la primera edición de Arauco Domado, aunque en ella se elogiaban los métodos utilizados por la política colonial para mantener en la sujeción a los pueblos. Con todo, en el poema constan muchos datos sobre la vida cotidiana en esa época y hay alusiones a la fauna y flora sudamericanas, así como acertadas metáforas del agua: el río es una "transparente vidriera", el arroyo está "hecho de puro vidrio", la "materia líquida y serena" donde se copian los árboles, no deja adivinar "cual es la rama viva — si la que está debajo o la de arriba". En otro poeta de los mismos tiempos, la poesía reviste un carácter cívico. Bernardo de Balbuena, altamente estimado por la sociedad colonial, llevó la mitra de Obispo de Puetto Rico, pero amaba con nostalgia a la ciudad de México, en loor de la cual compuso el poema Grandeza Mexicana, que es un manual de líricas alabanzas y un compendio de la actividad social de esa urbe "flor de ciudades, gloria del poniente". Se ha dicho que el poeta quiso halagar a los poderosos de México, y en esto no hay duda alguna, pero es menester aclarar que en el capítulo IV del poema, su autor no ensalza la riqueza o la situación sino los conocimientos, el ingenio y la 
sabiduría. Coloca a las aulas de México, en las letras y ciencias, a la altura de las de Salamanca, Alcalá, Lovaina y Atenas. Y, con expresión elocuente, afirma en sus musicales tercetos que en México hay más hombres eminentes "en toda ciencia y en todas facultades - en las letras humanas y divinas- eternos rastreadores de verdades".

Hispanoamérica es tierra de paradojas. En una sociedad en que la educación estaba exclusivamente en manos de la Iglesia y en que el pueblo no tenía acceso a la Universidad sino sólo a la escuela de primeras letras, los escritores gozaban de aprecio popular. Francisco de Terrazas, Jacinto de Evia - llamado "maestro" por sus contemporáneos-, Hernando Domínguez Camargo, vivieron ródeados de la aureola de la admiración pública en sus respectivos países. Los rasgos dominantes de estos poetas eran la religiosidad, el sentimiento de la naturaleza, la aceptación resig. nada de la organización colonial, la búsqueda de las verdades metafísicas. Pero, subterráneamente se abría paso una nueva corriente de ideas que expresaba su inconformidad con la sociedad de la época, mediante la sátira. Mateo Rosas de Oquendo, Juan del Valle Caviedes, son las figuras representativas de esa tendencia. Las saetas burlescas no iban dirigidas, sin embargo, contra el podet político sino únicamente contra ciertas prácticas condenables: la ignorancia de médicos y curanderos, las intrigas femeninas, la adulación de los cortesanos. La sátira tenía una finalidad moralizadora de las costumbres. A esta corriente se sumó la aparición del espíritu científico en las colonias. Los mexicanos Carlos de Sigüenza y Góngora y Sor Juana Inés de la Cruz muestran en sus vidas y en sus obras el conflicto entre el siglo barroco y escolástico en que vivieron y las ideas de la Ilustración que alcanzaron plena madurez en el siglo subsiguiente. Sigüenza y Góngora recibió los más altos honores en reconocimiento de su valía intelectual, juntamente con una pensión acordada por Luis XIV para que viviera en París.

El caso de Sor Juana Inés de la Cruz es ilustrativo del grado de consideración social alcanzado por la poesía en esos tiempos: La ilegitimidad de Juana no constituyó un impedimento para que la corte virreinal le abriera sus puertas y le prodigara sus atenciones. Pero el desengaño mundanal la conduce pronto al convento y en esta actitud coincide con la época, que es la del desengaño español, humano y metafísico. Esta idea la expresó diáfanamente Sor Juana en un soneto acerca de su retrato, al que llamó "engaño colorido". En realidad, esta expresión pudo aplicarla al mundo en su totalidad porque significa en el lenguaje de la poesía un espejismo, una ilusión, la fugacidad de la vida, disimulada por colores atrayentes pero efímeros. Sor Juana padeció el conflicto in- 
terno entre la ciencia y la fe, o más claramente entre su pensamiento racionalista, que buscaba la verdad, y sus sentimientos íntimos, inclinados al dogma religioso. Lucha dramática entre la mente y el corazón, cntre la inquietud científica y el deber. Sor Juana Inés de la Cruz reflejó en su creación poética el estado de la sociedad en que transcurrió su existencia.

Juan Bautista Aguirre, Pablo de Olavide, Juan de Velasco son ya poetas del siglo de las luces. Su obra está vinculada a las vicisitudes de la sociedad de su tiempo que vio la expulsión de los jesuitas de América, la confianza en la Ilustración o sea en la educación pública y laica, así como la aparición de una nueva filosofía política y social, encarnada en la Revolución Francesa. Aguirre y Velasco fueron desterrados a Italia como miembros de la orden ignaciana, pero encontraron aprecio en la tierra que les brindó hospitalidad. Velasco, poeta e historia. dor, compuso un libro antológico $E l$ Ocioso en Faenza, donde reunió las mejores producciones de sus compañeros de hábito y sus propias poesías -entre ellas un elogio a Mirabeau- para mostrar a Europa el grado de cultura alcanzado por América, inaugurando una especie de americanismo literario con mucha anticipación al que debía prosperar en el siglo XIX.

Juan Bautista Aguirre llegó a ocupar, por su saber, posiciones importantísimas en la Real Audiencia de Quito, su país natal. Adelantándose a Pasteur, sostuvo la teoría, revolucionaria en ese tiempo, de que la enfermedad no era producida por causas sobrenaturales sino por los "corpúsculos", como él llamaba a los microbios. Durante el exilio de la Orden de los jesuitas, fue Consultor Teológico del Obispo de Tívoli, Monseñor Chiaramonti, que más tarde recibiria la tiara pontificia bajo el nombre de Pío VII. La personalidad del padre Aguirre se destaca en el siglo XviII porque representa, como Clavijero en México, el humanismo de los jesuitas, que preparó el camino para la independencia de los pueblos hispanoamericanos. Entre los poemas de Aguirre, uno de los más celebrados es la «Carta a Lizardo», en donde el concepto de que "todo lo nacido mucre dos veces" se tepite al final de cada estrofa, creando una atmósfera de misterio. El poeta define filosóficamente la nada como la muerte. Todo ser viene de la nada y va a la nada. Concepto poco reli. gioso que encierra una idea materialista, enciclopédica. El padre Aguirre elaboró en ocasiones una poesía hermética que necesita una clave intelec. tual para ser descifrada. El poeta no tenía esperanza en la vida futura del ser, creía en la libertad e intervino en favor de los derechos del pueblo. En el Motín de los Estancos que tuvo lugar en Quito, en 1763 , Aguirre demostró ser elocuente y persuasivo orador de multitudes, a las que guió al triunfo temporal. 
No es fácil comprender la evolución hispanoamericana si no se examina la vida y la obra de hombres como Pablo de Olavide, en el cuadro del siglo xvir, cuando la Ilustración comienza a renovar la sociedad, a obtener una mayor justicia y ensayar medidas económicas más razonables. Olavide, nació en Lima, llegó a las mayores alturas de la influencia política y social no sólo en América sino también en España y Francia. En tierras españolas llevó a cabo su original proyecto de colonización agraria de Sierra Morena, cultivó la amistad de Jovellanos, Aranda, Floridablanca y otros ministros de Carlos III, y mantuvo un "Salón Filosófico", desde donde se difundían las ideas de los Enciclopedistas. Olavide era un hombre totalmente comprometido con la filosofía de la Revolución Francesa y con la independencia de las colonias hispanoamericanas. Perseguido por la Inquisición, que hizo con sus obras un auto de fé y le condenó a vivir encerrado en un monasterio, el pensador se refugió en Francia, donde la Convención le decretó altos honores y una corona cívica por los servicios rendidos a la sociedad. Contó entre sus amigos a Diderot, Voltaire, Grimm. Cuando perdió su fortuna por la bancarrota de la Casa Gueméenée, Catalina de Rusia le envió fondos para que viviera decentemente. Nunca abandonó su actitud en favor de la independencia hispanoamericana. Los diputados de los pueblos de América, reunidos en París, confiaron a Olavide y a Miranda la misión de negociar con Inglaterra la ayuda material para la campaña emancipadora. Miranda alcanzó a ver realizadas en parte sus aspiraciones, pero Olavide, ya octogenario, no pudo recoger el fruto de sus desvelos. Su drama personal, en las postrimerías de su vida, fue el conflicto científico-religioso. Olavide ejerció una gran influencia en la sociedad de su tiempo. Anunció el cambio de orientación de la conciencia americana hacia la luz guiadora de Francia y la nueva doctrina política de los derechos del hombre y la soberanía del pueblo.

En el siglo xix la poesía echa su raíz en la circunstancia social, fruto de la evolución o del paso de la sociedad colonial a la sociedad republicana. Los poetas son cantores de la igualdad democrática, bajo la égida de la libertad. Nacen las patrias en América. El patriotismo inspira los poemas de José Joaquín de Olmedo, cantor de Bolívar, el Libertador de cinco naciones. El poeta participó en la insurrección de los criollos contra la dominación española. Fue miembro de la primera Junta de Gobierno constituida en Guayaquil y, luego, Diputado a las Cortes de Cádiz, donde se distinguió por su actitud en favor de la abolición de las mitas, institución que consistía en el trabajo obligatorio y gratuito de los indios. Tal injusticia, como la Inquisición y otras instituciones anacrónicas, fueron 
suprimidas por las Cortes, debido a los esfuerzos de los Diputados del Nuevo Mundo. Las Cortes dictaron una Constitución política, según la cual la Nación española no reconocería al rey Fernando VII como so. berano mientras no jurase obediencia a dicha ley suprema. El documento fue firmado por la mayoría de los Diputados hispanoamericanos, entre ellos Olmedo. Pero, poco después, se impuso la reacción absolutista. Fernando VII volvió al trono y persiguió a los hombres que habían firmado el famoso documento constitucional. Olmedo fugó a Francia, junto con otros diputados liberales, y regresó a su patria cuando comenzaba la campaña de Bolívar y San Martín para consolidar el movimiento de independencia americana. El poeta escribió «La Victoria de Junín», en loor de la batalla decisiva de esa guerra. Con este poema aparece nuevamente en Hispanoamérica el género épico, pero como un canto a la libertad de los pueblos, como un poema pindárico en que surgen nuevos mitos. Olmedo fue nombrado Ministro Plenipotenciario en Londres y París. Gozó en su tiempo no sólo de celebridad internacional sino también del aprecio de su pueblo, que hizo posible su candidatura a la Presidencia de la República, aunque fue derrotado en la votación de la Asamblea Constituyente.

La sociedad republicana, de preponderancia mestiza, que había sucedido a la sociedad colonial, concedió una importancia de primer orden a la enseñanza de los oficios y exaltó el trabajo de la tierra. El gobierno de la República decretó la emancipación de los esclavos negros y dictó disposiciones especiales para la protección de los indios. La encomienda feudal se transformó en la hacienda, explotada con los mismos métodos del pasado. Se extinguió el Patronato Real y se firmaron concordatos entre el Vaticano y los Estados nacientes. La nueva estructura social se refleja en la poesía de Andrés Bello, en las fábulas de García Goyena, en las sátiras de Irisarri. El primero de estos autores cantó las faenas agrícolas en el trópico, exaltando la dignidad del hombre del campo. Hizo de su poema una proclama contra la guerra civil y un llamamiento en favor de la paz fecunda y civilizada. En sus comienzos, Bello desempeñó el cargo de Secretario de la Sociedad de Amigos del País, institución que era un semillero de patriotas y de ingenios literarios. Fue preceptor de Bolívar y, más tarde, Ministro Plenipotenciario ante la Corte de Inglaterra. Permaneció durante veinte años en Londres, donde mantuvo relaciones de amistad con los poetas españoles y americanos desterrados. Un poema típico de Andrés Bello es la "Carta de Londres a París, por un americano a otro", donde señala algunas verdades sobre la situación de Hispanoamérica y manifiesta que la obra de la emanci- 
pación no había traído aún la felicidad a los pueblos. La epístola está dirigida a Olmedo, su amigo fraternal que cumplía en París una alta misión diplomática. La nota característica de la poesía de Bello es su optimismo acerca del destino de América, por lo cual se ha llamado a su autor "el Virgilio de la nueva Edad". A semejanza del poeta latino que cantó, en el umbral de la Era Cristiana, la "edad de oro" próxima, el gran venezolano anunció la Edad Dorada de la independencia, de la democracia y el progreso.

Pero, las predicciones no se cumplieron. Después de la emancipación, el Nuevo Mundo se encontró en la ruina económica y en el caos, por no haber podido resolver los principales problemas políticos y sociales como la dominación oligárquica, la estructura feudal de la tierra y, sobre todo, la fragmentación de la "patria americana" en Estados. Era la época de los caudillos militares y de la penetración económica de las potencias europeas en América, principalmente de Inglaterra que llegó a controlar el comercio mediante sus inversiones y créditos. La Iglesia intervino en la política para conservar sus antiguos privilegios coloniales: la dirección de la enseñanza; la administración de hospitales y cementerios; el tegistro de nacimientos, matrimonios y defunciones; la exclusión de otros cultos. El Romanticismo iba a enfrentarse con las nuevas realidades.

Durante este período, los poetas estuvieron comprometidos en la lucha política por los derechos del pueblo contra las dictaduras y por la afirmación de la fisonomía nacional. El cubano Heredia, los argentinos Echeverría, Mármol, Sarmiento, el peruano González Prada y otros, sufrieron persecuciones y destierros por su actitud de oposición a la tiranía y a la ignorancia. Su insatisfacción ante el mundo material formaba parte de su angustia romántica. José María Heredia vivió en el exilio en México, José Mármol luchó contra el tirano Rosas, por lo cual fue encarcelado. Esteban Echeverría fundó el primer grupo socialista con el carácter de sociedad secreta. Sarmiento, creador de Facundo, conoció las asperezas del exilio pero también el júbilo del triunfo cuando, derrocada la tiranía, fue elegido Ministro y Presidente de la República.

Toda la poesía gauchesca se puede catalogar dentro de la literatura comprometida en favor de los derechos del mestizo de la pampa. Eficaz como instrumento de reivindicación de una clase social, la poesía gauchesca utiliza para su expresión la forma sencilla del romance en lenguaje popular. Las circunstancias creadas por la acción gubernamental precipita. ron la decadencia de la vida gaucha; pero Martín Fierro perdura porque es un canto a la amistad, exalta el color local, representa el nacionalismo en auge en esos tiempos y condena las injusticias sociales. 
González Prada y José Martí fueron reformadores de la sociedad. Ambos poseían una gran capacidad de rebeldía y una generosidad inagotable. El primero fue defensor del indio y del trabajador, o sea de las clases sociales desvalidas. Martí dedicó toda su energía a la independencia de Cuba, a la que hizo la ofrenda suprema de su vida. Fue la voz más pura de la conciencia cubana. La sencillez y la libertad constituyeron los dos grandes temas de su poesía en que expresa con facilidad y riqueza verbal los sentimientos más complejos, en un estilo condensado y detallista, impresionante por su sinceridad avasalladora.

A grandes pasos, hemos recorrido más de tres siglos de poesia hispanoamericana hasta llegar a los últimos lustros del siglo xIX, en los umbrales del Modernismo, donde se sitúan las figuras atormentadas de Gutiérrez Nájera, Julián del Casal y José Asunción Silva. Los tres poetas, modernistas por la forma musical pero románticos por el fondo, desde. ñaban la vida moderna y la sociedad burguesa. Sin embargo, su actitud inconforme no era combativa sino resignada. Cultivaban el deseo íntimo de abandonar la vida en plena juventud. Silva lo hizo por la puerta falsa del suicidio. El signo de esta generación de románticos tardíos fue la desmesura y el amor a la muerte, en contraposición al grupo encabezado por Darío, que proclamaba la mesura y el amor a la vida. Pero, existía un denominador común de ambos grupos: el refinamiento artístico.

En su libro The Modern Culture of Latin America (Society and the Artist) Jean Franco afirma que el poeta es un "outsider" en la sociedad hispanoamericana. Para reforzar este concepto, evoca, entre otros, los nombres de Lugones, Silva, Darío, y añade: "Mucho antes de escribir, varios de los modernistas habían ya comprobado, en el duro terreno de la experiencia, las crueldades y peligros de un mundo gobernado por el dinero o la fuerza". Esta afirmación no corresponde totalmente a la realidad, porque Darío y Silva fueron poetas precoces que comenzaron a escribir antes de llegar a la edad de la experiencia. Además, el hecho del predominio de la fuerza o del dinero no implica que el poeta sea un intruso, un extraño, ajeno a la sociedad a la que pertenece. En ninguna etapa de la evolución cultural de Hispanoamérica, el poeta ha sido un "outsider". Todo lo contrario: hemos visto que, desde los primeros días de la formación de la sociedad hispanoamericana, el poeta ha participado en sus vicisitudes o ha tomado posición contra ella, en defensa de la justicia. Esta posición ha alcanzado diversos grados, desde las sátiras encendidas de los poetas coloniales, las críticas demoledoras-de González Prada y el holocausto de Martí, hasta el nihilismo de Casal y de Silva. Los poetas modernistas comprendieron que la poesía debía cumplir una 
función social de educación estética del pueblo. No se alejaron del mundo como lo pretende el mito de la "torre de marfil", difundido por quienes no desentrañaron el sentido del Modernismo y creyeron era únicamente una innovación formal y un arte decadente para iniciados. El Modernis. mo fue algo más complejo: la búsqueda de la originalidad americana, una revolución rítmica, la renovación temática y su ampliación a una escala universal, así como la aceptación de la modernidad y la comprensión del futuro. Antes de su revelación de un arte nuevo, Darío era ya, a los dieciseis años, el primer poeta civil de su país y había dedicado mil versos a la exaltación del libro como una de las grandes creaciones humanas. Admirado por varios presidentes de la República, el poeta pudo salir de su tierra natal y descubrir nuevos horizontes. No sintió la so. ledad, lo cual le aleja de la poesía hispánica, pero tampoco se propuso crear una obra de contenido social, aunque en varias ocasiones fue el portavoz de la conciencia hispanoamericana en favor de la paz, la espe. ranza y el progreso. En los cuatro modos de poesía social -el histórico, el nacional, el político y el humanitario, clasificación hecha por Pedro Salinas- hay ejemplos aislados en la creación rubeniana. En el modo histórico se destaca el luminoso poema "Tutecotzimi"; en el modo na. cional, gran parte de la obra anterior a Azul, Trípico de Nicaragua y otros poemas. Los modos político y humanitario se fusionaron en diversos cantos donde Darío clamaba por la eliminación de la violencia. Un año antes de su muerte, a su paso por Nueva York, leyó en la Universidad de Columbia su poema "Pax", en el cual presentaba el cuadro de Europa en guerra y aconsejaba: "Llevad a los altares de la Paz, miel y rosas. Paz a la inmensa América. Paz en nombre de Dios."

En la primera década de nuestro siglo, la sociedad hispanoamericana experimentó varios cambios por la penetración de corrientes ideológicas contrarias: el socialismo, el positivismo, el liberalismo anticlerical, el nuevo idealismo. La doctrina socialista, utópica en sus inicios y romántica luego, se transformó en socialismo científico y empezó a organizarse con la intervención de la clase trabajadora. En París, comenzó la acción del Partido Socialista Francés con Jaurés en 1904, en los días en que Darío y otros poetas modernistas andaban por Europa. La Revolución Mexicana, iniciada por Madero en 1908, triunfó dos años después y abrió la era de la transformación socio-económica, en la cual la clase campesina desempeñó su papel sacrificándose en la contienda civil. Aparecen en la poesía las corrientes de ruralismo y exaltación de la vida sencilla con Lugones, Ramón López Velarde, Luis C. López y Enrique González Martínez, quien en un soneto evocador del consejo verlainiano de "torcer el 
cuello a la elocuencia", pide hacer lo mismo con el cisne de "engañoso plumaje", simbolo del exotismo suntuoso y de la aristocracia desprovista de sensibilidad.

Profundamente arraigada en el subsuelo social está la creación poética de Leopoldo Lugones, quien se declara socialista desde la época temprana de Las Montañas del Oro, pero en los últimos años de su vida abandona esa doctrina y proclama sus simpatías por una filosofía política diametralmente opuesta, fundada en la fuerza. Sin embargo, muchos de sus poemas constituyen un canto al esfuerzo colectivo argentino, a la vida laboriosa de los campos. Las enseñanzas de Andrés Bello parecen haber germinado en la obra de Lugones que nos ofrece, en grandes murales, la pintura de los pastos, donde engorda el ganado, y de las mieses, "doradas tribus" que desbordan su riqueza en la "pampeana inmensidad". Bucólicas nuevas, geórgicas del Nuevo Mundo, las Odas Seculares, los Romances de Río Seco y los Poemas Solariegos significan el intento mayor de crear una poesía auténtica de las costumbres, los persona. jes y los trabajos de una sociedad libre y activa. Los inmigrantes, los agricultores, molineros, hilanderas, labriegos, aguadoras, arpistas y demás gente sencilla, desfilan por los poemas descriptivos de Lugones, cuyas realizaciones estéticas le califican como el mayor poeta modernista, después de Darío, y como el poeta más alto del ruralismo hispanoamericano.

En el campo de la fe social, una abjuración semejante a la de Lugones fue la de Guillermo Valencia, quien escribió en su juventud el poema "Anarkos" — donde evoca la acción de los anarquistas en Fran. cia- mientras en su madurez mantuvo paradójicamente las más extremas doctrinas conservadoras. La plasticidad y el colorido parnasiano de sus versos le dieron una gran popularidad que le llevó a ocupar un sitial en el Senado de Colombia.

Dentro de horizontes más reducidos, Luis Carlos López, hombre de Cartagena de Indias, expuso en la galería humorística de su poesía los retratos de los personajes principales de la sociedad aldeana: el alcalde, las muchachas solteras, el cura, el barbero charlatán "que oye misa de hinojos y habla bien de Voltaire". La obra del poeta cartagenero es un mundillo animado y burlesco, una "comedia tropical", como se la ha llamado con acierto.

En una posición adversa a las consagraciones oficiales, floreció la poesía de César Vallejo, intérprete de la angustia del hombre contemporáneo, asediado por todos los peligros de una sociedad fundada en la usurpación del poder político y económico. La trayectoria de Vallejo comenzó con Los Heraldos Negros, libro de poesía directa, amarga, 
llena de alusiones a la vida cotidiana y a las costumbres de indios y mestizos de su tierra natal. En la evocación de cosas y personajes locales, el poeta acierta con el matiz típico: la "alegre procesión de luces", el arriero "fabulosamente vidriado de sudor", el "Romeo rural", la carreta "que lleva una emoción de ayuno", el suertero que vende los billetes de lotería y que "contiene no sé qué fondo de Dios". Tiempo después, en una celda donde estuvo encarcelado por su actividad política, Vallejo escribió los poemas de su segundo libro, Trilce, en un lenguaje visceral, enigmático, en cuyos peldaños inicia su ascensión a la esfera de la poesía trascendental. No obstante su actitud de insurgencia permanente contra las injusticias sociales y de solidaridad con las clases oprimidas, el poeta no consintió en introducir en su poesía los fáciles elementos del proselitismo político. En un artículo que publicó en 1928 - recogido después en su libro Literatura y Arte - decía: "Cuando Haya de la Torre me subraya la necesidad de que los artistas ayuden con sus obras a la propaganda revolucionaria en América, le repito que, en mi calidad genérica de hombre, encuentro su exigencia de gran giro político y simpatizo sinceramente con ella, pero en mi calidad de artista no acepto ninguna consigna o propósito propio o extraño que aún respaldándose de la mejor buena intención, someta mi libertad estética al servicio de tal o cual propaganda política".

Era la época en que se difundía por los países sudamericanos la doctrina de la incorporación del indio a la vida nacional y florecían las enseñanzas de la Revolución Rusa. En las regiones de numerosa población india aparecieron los poetas indigenistas. En el Perú y Bolivia se llegó al extremo de dar cabida en el poema a locuciones en lengua quechua, lo que circunscribió la poesía a ámbitos limitados dentro de la misma clase social que se pretendía redimir. Además, grandes sectores de ésta se encontraban integrados por analfabetos, lo cual explica la poca resonancia obtenida por la poesía de Alejandro Peralta, José Varallanos o Gamaliel Churata, auténticos animadores de la resurgencia de la clase indígena. Muchos otros poetas, lectores de Tolstoi y Gorki, escribieron cantos al hombre oprimido y a la revolución, en Chile, Argentina $\mathrm{y}$, particularmente, en México, donde agitó el ambiente el movimiento estridentista, representado por figuras de amplia formación literaria como Maples Arce, Lizt Arzubide, Luis Quintanilla. En el estridentismo se confundían algunos ecos de las escuelas más avanzadas como el creacionismo y el vanguardismo. En realidad, los referidos poetas no eran estridentes sino acuñadores de metáforas nuevas cuyo elemento esencial de sorpresa se orientaba hacia la realidad política, según lo demostró 
Maples Arce que supo apresar en sus poemas algunas imágenes características de la lucha social, como aquella muy conocida que compara el fulgor de la tarde con un "motín sangriento en los suburbios".

La guerra civil española vino a agitar la conciencia del mundo y, naturalmente, la del hombre hispanoamericano. Los poetas como Vallejo, Neruda, Nicolás Guillén, Octavio Paz, escribieron libros en loor del pueblo y de la república. Otros guardaron silencio, pero mantuvieron una actitud de simpatía por los principios democráticos. En este grupo figuraban los mexicanos Jaime Torres Bodet y José Gorostiza, el venezolano Andrés Eloy Blanco, los guatemaltecos Miguel Angel Asturias y Luis Cardoza Aragón. Su posición no ha impedido que la sociedad de sus respectivos países reconociera su alta valia intelectual como lo prueba el hecho de que casi todos han recibido la investidura de Embajadores Extraordinarios. Torres Bodet, Blanco y Gorostiza han ocupado además el alto sitial de Ministros de Relaciones Exteriores.

La poesía hispanoamericana del siglo xx —en particular desde 1930no sólo es fruto de la difusión de las ideas sino que tiende a transformar la sociedad de la que procede. El poeta es un hombre social que aspira a ser un guía de su pueblo y aporta su esfuerzo al afán colectivo, mediante la difusión de sus obras, pese a ciertas condiciones adversas, entre ellas la edición de libros, industria subdesartollada en Hispanoamérica y cuyos métodos anacrónicos no corresponden al nivel elevado de su literatura ni al crecimiento de la urbe moderna. Este atraso editorial ha sido superado en un solo caso, el de Neruda, quien ha encontrado una gran audiencia en las masas. Hace treinta años, el poeta confesó, en un himno a la patria, su labor proselitista:

Sali a encontrarte hijos por la tierra, salí a cuidar caídos con tu nombre de nieve, salí a hacer una casa con tu madera pura, salí a llevar tu estrella a los héroes heridos.

El tiempo se encargaría de convertir en realidad estas aspiraciones. En los cuatro extremos de la América hispana encontró eco la "poesía social", que no se ha extinguido aún y que parece substancial a la expresión del hombre de nuestra época; pero es menester no confundir esta poesía con la de cartel, en boga hace medio siglo y desaparecida ya, definitivamente, del horizonte literario. La poesía social de hoy extrae sus jugos nutricios de las zonas biológicas y ontológicas y constituye una forma de la experiencia humana. 
En su referido libro sobre la cultura y la sociedad, Jean Franco llega a conclusiones categóricas, entre ellas una muy significativa que viene a reforzar nuestra tesis: "La mayor diferencia (entre la cultura latinoamericana y la del resto del mundo) consiste no sólo en la obvia de razas $y$ paisajes distintos, sino en una que se refiere a las nociones fundamentales de la finalidad del arte. Mientras una parte considerable del arte occidental se interesa principalmente en las experiencias individuales y en las relaciones entre los sexos, las mejores obras de la literatura latinoamericana, y aún de su pintura, se preocupan con mayor intensidad de los ideales y fenómenos sociales". Más adelante, Jean Franco señala el amor a la humanidad como característica de la poesía his. panoamericana más notable. Estas afirmaciones descansan en sólidos fundamentos. Nuestra época se caracteriza por el despertar de la conciencia colectiva y por la realización de una gran aventura: la marcha de la humanidad hacia nuevos horizontes. Este hecho to ha expresado con claridad Torres Bodet, uno de los exponentes de la poesía hispanoamerica. na, estremecida por un nuevo humanismo:

No veremos la tierra prometida

ni su dorada miel disfrutaremos

ni el perfumado aceite de sus lámparas

alumbrará en la noche nuestros sueños.

......

No veremos la tierra prometida.

Nacimos y morimos en los tiempos del éxodo.

La era presente es de transición. El hombre vive acosado por toda clase de tensiones físicas, espirituales, colectivas, internacionales. Atravesamos nuestro período de tiempo como una vasta extensión inhóspita, como la "tierra estéril" de Eliot, al final de la cual se encuentran los suspirados manantiales que saciarán nuestra sed. En esta travesía de los últimos años, la sociedad humana ha comenzado a desdeñar la poesía por considerarla un ejercicio inútil. El crítico francés Roger Caillois ha señalado con razón dos fenómenos contemporáneos: $1^{\circ}$ ) el papel cada vez más restringido que desempeña la poesía, y $2^{\circ}$ ) la disminución de su importancia relativa en el conjunto de la cultura. En realidad, éstas son dos facetas del mismo problema de la deshumanización, ya viejo de más de medio siglo, y que encuentra su culminación en los nuevos mitos mecánicos y económicos. $\mathrm{L}_{a}$ sociedad experimenta la decadencia progresiva de la vida espiritual, como lo anunciaron algunas voces proféticas 
en el siglo xIx. Pero, esta decadencia lleva felizmente el signo de lo transitorio. El hombre llegará a las fronteras del vacío y volverá sobre sus pasos valiéndose de la poesía como un instrumento de salvación. Será el fin del éxodo y el comienzo de una era de comprensión universal.

Jorge Carrera ANDRADE

La Garenine, Francia 
